\title{
Cross-selling in the financial sector: Customer profitability is key
}

Received (in revised form): 18th December, 2001

\section{Yasar F. Jarrar}

is Research Fellow at the Centre for Business Performance, Cranfield School of Management and an Honorary Visiting Fellow in Total Quality Management at the European Centre for Total Quality Management, Bradford School of Management, UK. He has published numerous papers in the areas of performance measurement and management, and has worked as a consultant for various national and international organisations.

\section{Andy Neely}

is Professor of Operations Strategy and Performance. Andy has been researching and teaching in the field of business performance measurement since the late 1980s. He chaired the first and second international academic conferences on performance measurement in July, 1998 and July, 2000 respectively and has authored over 100 books and articles on the subject, including 'Measuring business performance', which was published by The Economist. He has consulted to and worked with numerous organisations.

\begin{abstract}
Customer relationship management (CRM) is a growing trend in banks today and billions have already been spent on CRM systems. Financial service providers (FSPs) are, however, recognising the many challenges they face in implementing an enterprise CRM business strategy. This paper provides an overview of research work undertaken, in partnership with a major UK bank, to assess the validity of the 'sales through service' concept. The project aimed at identifying the requirements for a successful cross-selling system to provide an external input to the current initiative already underway at the bank. The paper aims to summarise the work undertaken to present what is believed to be a considerable gap between what CRM literature publishes and the actual implementation in 'real-life' organisations. It concludes with recommendations for developing the cross-selling initiative at the bank.
\end{abstract}

Dr Yasar F. Jarrar Centre for Business Performance, Cranfield School of Management, Cranfield MK43 OAL, UK.

Tel: +44 (0) 123475 1122; Fax: +44 (0) 123475 7409; e-mail: Yasar.Jarrar@ cranfield.ac.uk

\section{INTRODUCTION}

Customer relationship management (CRM) has become the buzzword of e-business, and it seems that there are almost as many definitions for CRM as there are vendors promoting products for getting closer to customers. Hence, there is little consistency on how CRM fits into an organisation, ie is it customer care, marketing, sales, all of those, others? In essence, CRM aims to increase the profitability of the customer portfolio. This may comprise many elements like customer acquisition, price, cost to serve, cross sales (further sales to the same customer), up sales (where the customer makes greater use of the same product or services) and so on. As argued in this paper, however, despite all the hype surrounding CRM in the financial services industry, as well as the solutions provided by vendors, financial service providers (FSPs) are recognising the many challenges they face in implementing an enterprise CRM business strategy. 
The Centre for Business Performance undertook a study in partnership with a major UK bank to help identify the business rules for a main application of CRM, namely cross-selling financial services. This paper summarises the study undertaken in three main parts. The first part of the study comprised a literature review and intended to provide a quick overview of the literature to help understand the concept of cross-selling, and shed further light on the ability of IT to facilitate cross-selling for customers in the financial sector. The literature overview attempted to cover published experiences and case studies presented by other organisations.

The second part focused on analysing the literature (cases and theories) researched to distil the business rules and best practices for cross-selling. Case studies were analysed systemically and the findings were presented in a framework that provided a holistic view of what are seen as the key ingredients for a successful cross-selling initiative.

Finally, the third part is an overview of the status quo of the bank's systems (those related to cross-selling business rules). Based on the generic framework developed, the study attempted to identify where (and if) these ingredients are available at the bank, where the data are kept, how they are managed, by whom and to what degree they are integrated. A 'data map' was developed at the bank based on background information and personal interviews, and proposals for the way forward were recommended.

This paper provides an overview of the research undertaken, the framework of business rules developed, and the data map. Moreover, the paper explores the role of customer profitability data within the framework and thus provides the context for using such information in a value adding approach for cross-selling.

\section{CROSS-SELLING IN THE FINANCIAL SECTOR: LEARNING FROM ORGANISATIONAL EXPERIENCE}

Information technology-based CRM and cross-selling seem to be growing trends in banks today. In banks the world over, billions have already been spent on CRM systems. Attempts have varied from installing database management systems to implementing enterprise-wide CRM systems. Not surprisingly, the results have ranged from total failure to weary success and positive future outlooks.

The attraction and retention of a firm's most valued customer is the bedrock of any CRM implementation. It is generally accepted that it costs five times more to acquire a customer than to retain an existing one. It is thus clear that one of the major principles for cultivating relationships with customers is to focus the company on increasing its 'share of the customer wallet' with each individual customer. $^{1}$

Full-scale cross-selling, however, is a largely untapped marketing strategy for many financial organisations. Broad-based financial services companies are trying to provide a one-stop shopping experience for customers as a way of retaining them for life. Many banks have invested in CRM systems and are already testing this theory.

A survey of experiences in European banks ${ }^{2}$ revealed that there were limited success stories depending on the country, the type of financial institution and the type of product/service sold. There are, however, various challenges, in a worldwide basis. As much as insurers and banks would like to package insurance and banking products, the regulators and the pressures of disclosure as well as new distribution channels such as the Internet are working in the opposite direction. There is pressure towards individual 
products with very transparent product charges, as opposed to the packaged policies where the charges are more obscure. $^{3}$

Some organisations, like PNC, ${ }^{4}$ reported implementing advanced CRM technology but no results were reported, and it was viewed as an investment to pay off in the future. A few organisations, however, did report successful cases like the Woolwich (the UK mortgage bank) which, in 1997, decided that it needed a customer rather than a productcentric proposition based upon flexibility and convenience to the customer, and embarked upon its Open Plan strategy. ${ }^{5}$ This resulted in some business benefits, including a rapid growth in customer numbers, and a reported increased share of wallet. BBVA $^{6}$ had also reported similar successful outcomes. These cases demonstrated the most critical success factor for CRM: it should be a business strategy that requires a shift in focus from a product-oriented mentality to a customercentric approach. This, as demonstrated by the Woolwich, requires changes in products, structures, organisational culture and information technology (IT) systems.

Other cases, like Wells Fargo, ${ }^{7}$ have reported partial success for their cross-selling efforts which, upon studying the facts and circumstances of the cases, are arguable. These are cases where banks have merged or acquired other banks, and managed to sell some of their products to the new customer base. Such cases are heavily reliant on non-organic access to a huge customer base and can not wholly or even largely, be attributed to CRM strategies. They are more the result of advanced new customer-product matching software/databases, and targeted marketing campaigns (tools in CRM systems, but neither holistic in nature, nor as expensive as the whole CRM strategic approach). And a lot of eyes will be watching Citigroup/Travelers to see just how successful this landmark financial holding company becomes. ${ }^{8}$ Cross-selling was a key objective behind the merger between the Travelers Group and Citicorp in 1998, 'an objective that so far has been elusive'. ' Overall, plenty of other financial giants have taken a crack at cross-selling, mostly with little success. In fact, various surveys ${ }^{10}$ and industry experts ${ }^{11}$ seem to agree that CRM in general has not been able to show demonstrable payback.

\section{CRM-BASED CROSS-SELLING: HOLY GRAIL OR ACHIEVABLE GOAL?}

In theory, for banks that are up to the challenge, the rewards of mastering CRM-based cross-selling can be substantial. Many bankers and experts believe that 'as the various sectors of financial services gradually converge, customers will gravitate to providers who can blend financial services into one compelling value proposition'. ${ }^{12}$ Moreover, the sheer increase in Web traffic overall should boost customer contacts at bank sites. Getting those customers to consolidate their financial services with a single institution requires, however, a lot of convincing to show customers the value to them, and a seamless experience (from an IT on-line perspective). ${ }^{13}$ Managers cannot ignore any of these CRM trends and should measure customer expectations, relationship complexity, the reasons that drive customers to leave and the level of demand for mass customisation. ${ }^{14}$ How best to approach this task is, however, still under study. FSPs are being pressured to be more customercentric and develop enterprise CRM strategies. The promise of CRM, however, still eludes most FSPs because of a lack of 
definitions and technology solutions that integrate business goals. ${ }^{15}$

The main points that came through from the literature review regarding CRM-based cross-selling in FSPs were:

- most of the evidence provided in the literature is basically anecdotal referring to organisational experiences with hindsight and very few have documented any numbers to show related measures or costs (apart from the cost of IT installations)

- the concept of cross-selling, and using IT to facilitate that process, seems to still be in an embryonic stage (hardly any banks noted that they have any such initiative older than two to three years). Thus very few are able to provide any evidence of its success (or even failure). Most view it as an investment waiting to pay off

- in some instances, there is conflict between the opinions provided in the literature (for and against) reflecting different attitudes, and indeed different experiences with IT enabled cross-selling.

Overall, IT-enabled cross-selling is still a developing concept in banks (with some more advanced than others). It is very complicated and will only be beneficial if it is approached in a well-planned manner, ie it can be a successful venture, or an expensive mistake depending on how well the process is planned, managed and monitored. With today's dazzling and seductive technology, enterprises must carefully calculate and understand the benefits they will gain and must realise that CRM and e-CRM investments may not show quantifiable benefits in the short term ${ }^{16}$ — and, as CRM is a young discipline, none have achieved long-term status yet to demonstrate the full long-term benefits. In this context, it is important for any organisation to develop a better understanding of what critical factors have to be considered when planning for CRM based cross-selling.

\section{BUSINESS RULES FOR IT-BASED CROSS-SELLING}

The objective of this part of the study was to provide a framework of business rules to guide the sales through service initiative at the bank. The inputs to this framework were mainly experiences of other organisations (case studies of leading financial institutions) and basic theories and research related to cross-selling in general and the financial sector specifically. Hence, the resulting framework can be viewed as a generic best practice approach.

The goal of the sales through service system is to understand customers so the organisation can tailor any offering to them, at a profit: what are they buying, what would they buy, what financial products are they buying from other companies, what market segments are they in, what are the purchase-behavioural characteristics of that segment, what is the composition of those households, where are they with respect to lifecycle need, how to best approach the customer (which channels, when, what to say), how to measure their reactions, how to ensure satisfaction, what skills do the workforce need, how to motivate them, what systems are required to support them?

Figure 1 provides an overview of the cornerstone ingredients that must be tackled successfully to develop such a system. What follows is an overview of these ingredients.

\section{IT infrastructure}

There are two primary design requirements to ensure that all the pieces 


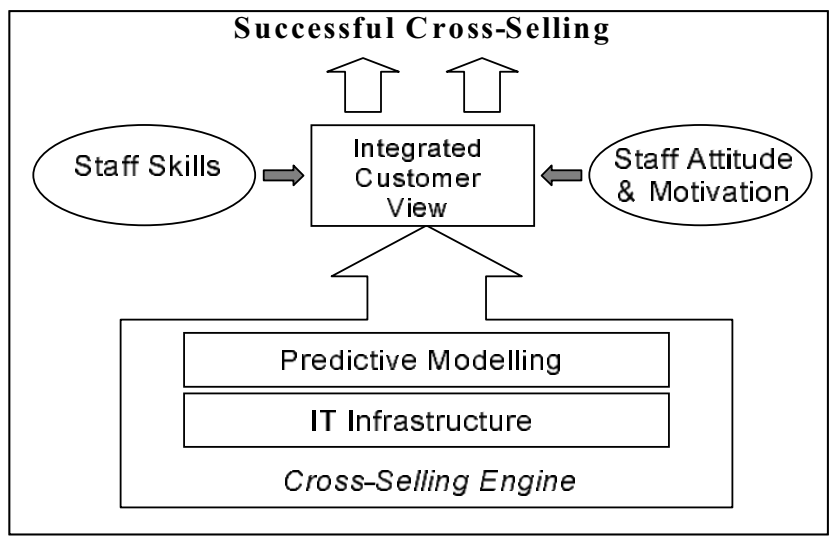

Figure 1 A framework for a best practice IT-based cross-selling system

come together at this stage: common standards for core systems (for database structure, for example) so that separate systems can be linked, and a central databank that is accessible to all. ${ }^{17}$ In this context there are two different types of technologies that support a customer relationship strategy:

- CRM, the customer-facing, interaction systems, such as support, campaign management and sales force automation

- customer intelligence (CI), which provides tools to capture, store, process, access, organise and analyse/model customer data. The results of this analysis are typically put into action via the CRM systems.

Clearly, this is the area where most banks do, eventually, get it right. It requires considerable investment in patching up old technology and acquiring new systems. There is no lack of CRM systems and e-CRM system vendors and consultants, and most banks do rely on them.

\section{Predictive modelling system}

Predictive modelling builds behavioural models to predict response rates, cross-sell opportunities, fraud potential, churn candidates and creditworthiness, etc. ${ }^{18}$ CRM techniques to maximise cross-selling potential include: ${ }^{19}$

- using transactional triggers/events to deliver relevant messages to customers

— improving targeting of direct marketing campaigns through the use of behavioural propensity and segmentation models

- using contextual triggers to deliver relevant messages to customers.

A reliable predictor of future behaviour in humans is past behaviour, which is why transactional information is important. A culture must be fostered that continuously gathers customerspecific information that enhances the customer information database. Every encounter must be seen as another opportunity to find out additional information. ${ }^{20}$

There are, however, some drawbacks. The assumption that usually underlies CRM technology is that customers are rigid individuals who express 'normal' behaviour all the time. In fact, much of the predictive technology assumes a normal distribution of the market segment that has a particular behaviour and that this behaviour falls within the 
specified confidence interval. There is evidence that such 'normal' behaviour does not necessarily apply all the time. ${ }^{21}$ Predictive technology also assumes a direct causal relationship between two different products or among multiple products. The direction of this causality in these relationships is actually unclear. Thus, while the predictive modelling is an important ingredient, it is not enough on its own. Much has to rely on the bank's own people who must be trained and empowered to listen and talk to the customer. The main message here, as with other areas in the study, is not to place too much reliance on IT and forget the business process and its people.

\section{Constructing the 'cross-selling' engine}

The following components were cited as essential inputs to build a successful 'cross-selling' engine:

- product/service lines knowledge: what products/services are provided, what the customer needs are, what products/services 'go together', ${ }^{22}$ what their features are, etc.

- piloting and script testing: in many organisations' experiences, banks that have taken a more modest, gradual approach — building competitive advantage in certain geographic regions or product segment by product segment, and learning by trial and error - have made considerable gains. 'Those tempted to go for the "big bang" should re-examine the rationale behind their strategy" 23

- contact rules: policies must be set based on all the ingredients to the system (360 degree view of the customer and predictive modelling) to generate the 'rules of engagement' (when to talk/send to a customer, what is the content, how to approach, etc.). ${ }^{24}$ Policies, however, must only be an enabler to trained and empowered staff who are in contact with the customer as only they can assess the right time, and appropriateness of the situation

- real time: the system's goal should be to bring all of a customer's data together on demand. It must be designed to take customer information from call centres, websites and information updates (like billing status), create a comprehensive profile of the customer, and make it available to anyone who might need it.

Compaq modelled a system with one billion transactions providing real-time updates to a simulated 40,000 representatives ${ }^{25}$

- consistency: "The key to realizing the potential value of a cross-selling program, no matter what approach you follow, is consistency of effort'. ${ }^{26}$ The more advanced systems track the offers a bank has already made, and provide consistency, control and coordination over all sales channels. ${ }^{27}$

\section{Sales skills and attitudes}

The key to a successful cross-selling system, which is forgotten by some banks, is the ability and motivation of their sales force. Technology is only an enabler for CRM. After all, it is the people who will use the system, implement the plans and talk to the customers. Many CRM systems fail due to failure to adopt the new system, and many did not achieve good results because of untrained staff. ${ }^{28}$ 'Skills development/transfer is the key issue, not IT'. ${ }^{29}$

The following have been identified as best practice in this area:

- know the sales force: their product knowledge, their sales skills, their knowledge of customers, and especially their attitudes and preferences 
— train staff when to go for sales opportunity: training needed covers a range of skills including sales and listening and account rounding

- make cross-selling a priority: commit the necessary resources and instil disciplined management supervision. Managers need to work with customer-service representatives in integrating cross-selling into their daily work process

- customer-service representatives have to know cross-selling is part of their job. They need discipline to discuss the benefits of full account coverage with one agency proactively

- staff must take ownership of the customer. ${ }^{30}$ Representatives in best practice companies maintain contact with the customer throughout the process to ensure that their question or issue is ultimately resolved

- quality assurance: this can be done via random monitoring to ensure compliance with using the script correctly, positive reinforcement of positive habits (eg catch the sales representative doing something right), and listening to the customer recommendations to the bank ${ }^{31}$

- reward and recognition: it is critical for everyone in the organisation to benefit from the programme. Agents and customer-service representatives should be compensated for their roles in the process. ${ }^{32}$ Sales are usually rated on salesmanship, customer relationships, compliance and technical skills. ${ }^{33}$

\section{An integrated view of the customer}

The objective of the information to be integrated here is to have an entire financial/personal snapshot of a customer on one engine (360-degree view). The data that should be integrated in this engine include the following.
1. Customer satisfaction - main ingredients include satisfaction surveys, customer feedback (usually in the form of voluntary feedback, eg completing prepared cards in branches), and customer awareness surveys (can be incorporated in other surveys, mainly to understand how familiar customers are with the bank's products, processes and their willingness to recommend it).

2. Customer needs - mainly identified through surveys (postal, interview based, over the phone, over the Internet (website)).

3. Customer complaints - problems reported via all channels and the responses provided. These data are essential in preparing contact plans (both content and timing) and should drive or suppress sales actions.

4. Customer loyalty (retention analysis) - usually measured by studying customer behaviour in respect to transactions. Customer loyalty can be demonstrated if they take part in cross-buying, up-buying, repeat purchases and persistency in the relationship with the bank. Other measures of loyalty can be inferred from customer satisfaction surveys and customer awareness surveys. This type of information should be mainly used to manage communications with customers, manage promotions and evaluate investments.

5. Customer personal profile - the importance of updating customer files is paramount. If companies want to cross-sell effectively, one of the first things they need to do is focus on updating the demographic information about their customers. ${ }^{34}$ Best practice contact centres house a wealth of customer information in their databases, which allows representatives to talk with the customer on a more personal level. ${ }^{35,36}$

6. Customer financial profile including items like risk scores, credit 


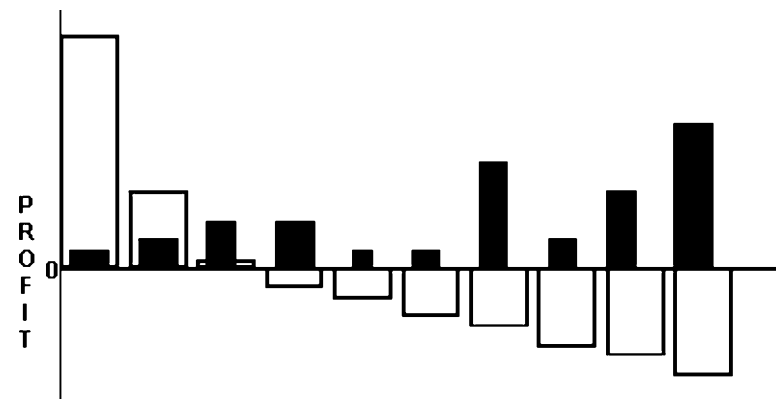

Figure 2 Current (white) and potential (black) customer profitability (UK building society)

scores, etc., to create a risk profile showing the risk profile of individuals/households for each product and on an aggregated basis, so as to indicate which products should be offered to which customers.

7. Customer holdings — including product range held by customer and purchasing profile.

8. Customer contact history — details of when the organisation was in touch with the customer including marketing campaigns, and other contacts (organisation or customer initiated) and the customer responses to these contacts across all touch points.

9. Customer segmentation - once a single view of the customer base and their potential profitability is in place it is possible to identify and segment the target market. Segmentation of future target groups can be based on customer need, behaviour and value. ${ }^{37}$

10. Customer profitability — among many others, Gartner Group research ${ }^{38}$ has illustrated that customer profitability analysis can form the cornerstone of successful CRM. It has been argued that cross-selling can actually be detrimental to an institution unless it is tied in closely to customer profitability analysis. In other words, selling more products to an unprofitable customer may simply make that customer even more unprofitable. ${ }^{39}$ 'Knowing one's customers vary in value allows the organisation to concentrate on the types of customers who are more likely to generate meaningful profits for the business'. ${ }^{40}$ Research revealed that 20 to 30 per cent of customers produce the most profit for a bank. Another 20 to 30 per cent are typically moderately to wildly unprofitable customers. The remaining customers are around the break-even to moderately profitable point. ${ }^{41,42}$ Applying broad strategies, such as shedding all unprofitable customers or trying to increase the number of products per person, are unlikely to increase the bottom line. ${ }^{43}$ Different profitability categorisations require different emphasis on retention, cross-sell and service modifications. Figure 2 shows current customer profitability (white bars), and the potential (black bars) at a UK building society. ${ }^{44}$ By showing the opportunity lost, and the potential profit, the figure clearly reveals the need to re-design the marketing and targeting plans based on customer profitability measures.

Organisations that decide on major investment in CRM technology should pause and ask themselves whether the customers are worth it. A US-based survey ${ }^{45}$ reported that just over half the national sample (52.2 per cent) report they do not measure customer profitability. Of those banks that do measure it, half do not take any action based on the data. As for the other half, 
29.9 per cent use the system to target unprofitable customers for increased cross-selling; 12.3 per cent use pricing to encourage them to go elsewhere; and 8.7 per cent attempt to guide them towards cheaper, more automated options.

Banks must close the loop and measure the effectiveness of their CRM initiatives on bottom-line contributions. Failure to do so will result in ignorance about how marketing, sales and service decisions are affecting overall profitability and the lack of a mechanism for refining initiatives to increase customer value. Gartner Group ${ }^{46}$ estimates that by 2004 , more than 60 per cent of banks will not know if these decisions are significantly increasing their bottom lines because they will fail to measure the effectiveness of their CRM initiatives based on profitability contribution.

Therefore, to be sure that their CRM initiatives are increasing profitability, banks must close the loop and measure the results of their CRM efforts based on profitability. Many banks measure marketing, sales and service initiatives, but few measure them based on profitability. ${ }^{47}$ Research indicates that banks have been slow to use profitability analysis as a measure of success for marketing campaigns and cross-selling. According to a survey ${ }^{48}$ of more than 200 US banks, most banks measured their 1999 marketing campaigns based on the number of sales, the dollar value of sales or response rates. Less than 35 per cent of the responding banks measured the results based on the profitability contribution to sales overall or the contribution of sales to individual customer profitability. For cross-sell campaigns, banks predominately measured results based on the number of cross-sells. Less than one quarter measured cross-sell effectiveness based on the contribution of cross-sell to overall profitability or to individual profitability.
Calculations of current customer profitability, however, are not trivial and because banks face competing priorities, these calculations will be difficult to develop. In trying to understand customer profitability many organisations attempt to use proxies (account balances, multiple accounts, particular product used, sociodemographics, visits to facilities) ${ }^{49}$ instead of 'actual' costs as a basis due to difficulty in measuring actual costs. There are more detailed methodologies that should be followed to provide a clearer picture ${ }^{50}$ to attempt to understand the actual customer cost and profitability over the relationship timeframe (long-term value, LTV). An example was presented by NCR. Sitting atop NCR's Teradata data warehouses, 'value analyzer' measures profit at a very granular level by rating individual customer accounts based on five factors of income, expense and risk. These include net interest revenue, fee-based and other revenues, direct expenses (such as those related to transaction processing), indirect expenses and the anticipated risk associated with each account (based on NCR's risk-provisioning module); plus, to customise the system, the bank has also added a sixth factor: cost of capital. Value analyzer generates a score for each of these measures to develop an overall score for each account. Value Analyzer's primary purpose is to measure profitability as part of a bank's CRM strategy. The software supplies information about what customers are doing today plus supports the bank's projections about customer relationships five years down the road. ${ }^{51}$

\section{DATA MAPPING}

This final part of the study overviewed the status quo at the bank, regarding the sales through service initiative. The bank was already implementing a pilot at one 


\begin{tabular}{|c|c|c|c|c|}
\hline \multicolumn{5}{|c|}{ Reference \# specific to mapping process } \\
\hline Data Item & eg custc & satisfactio & evenue & \\
\hline Original Source (how is it generated) & \multicolumn{4}{|c|}{ eg customer surveys, billing } \\
\hline Location (where is it stored) & \multicolumn{4}{|c|}{ eg CIF, standalone $P C$, files } \\
\hline Storage Medium & \multicolumn{4}{|c|}{ eg paper, electronic database } \\
\hline \multicolumn{5}{|l|}{ Owner (who is responsible for it) } \\
\hline \multicolumn{5}{|l|}{ Frequency (collection or update) } \\
\hline Access (who has access to it) & \multicolumn{4}{|c|}{ eg all, management, sales advisers } \\
\hline \multicolumn{5}{|l|}{ Who uses the data } \\
\hline \multicolumn{5}{|l|}{ How (for what) is it used } \\
\hline Cost to capture & People (Hrs) & Material & Equipment & Other \\
\hline \multicolumn{5}{|c|}{$\begin{array}{l}\text { Issues Any more details, eg same data stored in different locations, similar items stored on } \\
\text { different IT platforms, data inaccuracy problems, etc. }\end{array}$} \\
\hline
\end{tabular}

Figure 3 Data mapping template

of its branches, and this section of the report provides an assessment of the current systems and infrastructure against the identified best practice business rules and components. The main objective is not to provide a 'yes/no' answer, but to provide some thoughts on areas for potential improvements, and highlight some issues that need further attention.

This stage was based on a best practice standard template of 'data mapping' to collect this information from known keepers. The proposed data mapping template is shown in Figure 3.

The data mapping process had to rely on the research team's involvement in interviews and discussion with various parties to get a realistic picture. It was planned that the map would be constructed along the same lines as the best practice business rules for cross-selling to identify whether the required information and components were in place, integrated and clear. The project team conducted in-depth interviews with personnel from all units of the bank and from various levels covering: business banking, personal banking, IT and research and development. Moreover, having constructed the data map, it was important to validate its contents from various sources. A list of key people were sent the final draft to gain their approval and feedback, including original interviewees and additional sources like the data protection officer and several users.

The data map was finalised and studied. Due to its confidential nature, Figure 4 demonstrates an illustrative example only (selected parts of the map with sample information). The map highlighted several key points:

- the bank already had in place systems to gather all the components noted in the best practice business rules

- the data gathered differed in sophistication and depth for each 


\begin{tabular}{|c|c|c|}
\hline Requirements & System Names & Data Locations \\
\hline \multicolumn{3}{|c|}{ 1. Integrated View of the Customer } \\
\hline $\begin{array}{l}\text { Customer Needs } \\
\text { Identification }\end{array}$ & Pilots in place & \\
\hline $\begin{array}{l}\text { Customer Feedback } \\
\text { (complaints/compliments) }\end{array}$ & $\begin{array}{l}\text { - Complaints Dbases (Unit Responsible) } \\
\text { - Fragmented by: Location; Type of Customer } \\
\text { (personal, etc.); Method of complaint (letter, } \\
\text { phone, etc); Product type (visa, mortgage, } \\
\text { etc.); Several systems (respond, communicator, } \\
\text { access); Type of complaint (escalated, normal, } \\
\text { etc.) }\end{array}$ & $\begin{array}{l}\text { Multiple locations } \\
\text { across business } \\
\text { units (20) }\end{array}$ \\
\hline $\begin{array}{l}\text { Customer Profile } \\
\text { (Demographics) }\end{array}$ & $\begin{array}{l}\text { - Customer Information File, Fixed Term (Excell) } \\
\text { - Marketing DB } \\
\text { - Data Warehouse XX (holds DOB, postcode, } \\
\text { marital status, home status, sex, salary band, } \\
\text { employment status, tax status, BoE Industry } \\
\text { code, nationality, Geo-demographic) }\end{array}$ & $\begin{array}{l}\text { System Name } \\
\text { XXX }\end{array}$ \\
\hline \multicolumn{3}{|c|}{ 2. Predictive Modelling Techniques } \\
\hline \multicolumn{3}{|l|}{ Customer Transactional Data } \\
\hline \multicolumn{3}{|l|}{ Credit Rating/Scoring } \\
\hline \multicolumn{3}{|l|}{ Propensity Model Score } \\
\hline \multicolumn{3}{|l|}{ Behavioural Scoring } \\
\hline \multicolumn{3}{|c|}{ 3. Sales Skills and Attitudes } \\
\hline \multicolumn{3}{|l|}{$\begin{array}{l}\text { Sales Force Attitude/ } \\
\text { Preferences }\end{array}$} \\
\hline \multicolumn{3}{|l|}{ Staff Satisfaction Survey } \\
\hline Staff Training & & \\
\hline
\end{tabular}

Figure 4 Sales through service requirements - data map at the bank (sample only, map not complete)

component and in many areas there are several opportunities for improvement of the type of data, method of collection and use

- the data gathered are not integrated and this is the main obstacle revealed so far

— in many areas there were pilots for improvement and these, if well coordinated, can form the base line for future integration

- some areas need to be revisited with questions in mind like 'are we asking the right questions' and 'do we have the right measures in place'.

Moreover, the bank had undertaken a pilot to assess the effectiveness of the sales through services concept. It was a controlled experiment in one branch and the staff involved were those who volunteered. The pilot revealed several issues:

- the cross-selling scripts were adhered to 100 per cent for regulatory 
requirements. Due, however, to the mechanistic nature of the process, agents had to sell a product even if they felt it inappropriate (due to targeting measurement in the system)

- there were some flaws in the performance measurement system for the whole process as no data were held on how successful sales were. Data captured related to the number of leaflets etc. sent out and not actual conversions

- pilot saw staff being offered the opportunity to volunteer for the pilot, the staff taking up the offer were those already disposed to sell and should have a greater disposition toward sales.

The implications of this pilot were that although the initiative resulted in good results in successful cross-sells, it was felt that these were mostly due to staff ability to understand customer needs and discuss potential requirements and had little to do with the IT system that supported the process. In fact, the IT system that highlighted 'propensity' and 'likeliness to buy' and provided sales scripts was seen by some staff as a hindrance rather than help.

\section{ISSUES FOR FUTURE CONSIDERATION}

Having reviewed the experience of other organisations at implementing cross-selling, and having assessed the current approach and system at the bank, the following issues and gaps have been noted, and are listed here as areas to think about and improve where appropriate. These issues should be seen as potential problems that can occur, areas for future/immediate improvement, or areas that require further investigation. Although these resulted from a case application at the bank, they can be seen as generic issues that potentially affect various organisations in similar positions.

1. Capacity plans - when all the multichannel initiatives are up and running, and the sales through service is fully deployed, can the back office support this? Capacity plans and outlooks for the bank for the future 'currently' should focus on this capability and capacity building to provide the ability to deal with a possible large influx of customers. 'Cross-selling is not a big technology problem unless your organisation faces scale issues' says an IT executive at Chase Manhattan.

2. Customer relationships - the bank might jeopardise customer relationships by excessive and or repetitive (duplicated) contacts with a customer. Due to the lack of IT integration, there is the risk of offering the customer the same offer via two different channels in a short time period.

3. Sales force compensation and training - it is critical for everyone in the organisation to benefit from the cross-selling programme. Agents and customer service representatives should be compensated for their roles in the process. 'We made cross-selling part of the corporate culture. We told our employees this was the reason we were in business. We put incentives to cross sell into the compensation programme' said Mr Pulmeri, Citibank's Retail Branches and Credit Cards Director. ${ }^{52}$ Moreover, it is critical to provide the appropriate training for customer-facing sales force, both in terms of selling skills and product and service knowledge. Such training will require investment in time and money, and will require clear planning to decide on the mix of skills to be acquired (specialist versus generalist). Such decisions will be part of the overall CRM strategy.

4. Product re-design — without a clear, compelling value proposition, the power of marketing is limited. What, for 
example, is the point of building a marketing database or developing attractive promotional and enrolment materials if the product is a high-load, unbranded product or service that no one wants? ${ }^{53}$ The Canadian Imperial Bank of Commerce's VP credited the success of a campaign to a 'combination of targeting the right customers, being able to predict their responses, and having a very good offer'. ${ }^{54}$ In the UK, a recent government investigation found little differences between the current accounts offered by the big banks. ${ }^{55}$

5. IT investment and integration 'The biggest post-Y2K IT expenditure for financial institutions will be investment in better platforms for mining customer intelligence. The reason is simple obsolescence. In many cases, data warehouses built three to five years ago do not support finely targeted marketing and cross-selling over multiple channels. At the same time, the channels themselves are creating more challenges, as online financial services divert rich sources of customer intelligence outside the purview of the institutions'. ${ }^{56}$

6. Customer profitability analysis some have argued that cross-selling can actually be detrimental to an institution unless it is tied closely to customer profitability analysis. In other words, selling more products to an unprofitable customer may simply make that customer even more unprofitable. Moreover, once an efficient system is in place to understand customer profitability, the bank will face issues regarding what to do with unprofitable customers, and how to focus on profitable ones. Issues in this area will include channels of contact, products and service mixes delivered, charges, etc. In discussing customer profitability analysis (CPA) and long-term value (LTV), there needs to be recognition of the fact that an organisation's selling and marketing expenses are themselves major components of CPA and LTV, and the equation is interactive. The goal is to maximise customer LTV by investing the right amount and type of sales and marketing effort for each customer. Some customers should receive a lot and some should receive none. Some customers might even be encouraged to deal elsewhere if they cannot be made profitable and offer no other benefit to the organisation.

\section{CONCLUSION}

The business buzzword of the new millennium is CRM, with many firms displaying the same 'implement it quick' thinking as was applied to earlier management fads and fashions such as business process re-engineering (BPR) and enterprise resource planning (ERP), without appraising the real business benefits and linkages to future strategy. The potential danger is that retail banks see CRM as a panacea to future success. 'Merely by implementing a customer management software package the business can at a stroke improve customer retention ratios, increase cross-selling and reduce costs. Such aspirations are misplaced and often fuelled by a blind belief in the technology. ${ }^{57}$

CRM as a whole is an embryonic concept and many organisations have already invested a lot of money in it. Most believe it will pay back. So far, however, and from the published experiences, there is no evidence to show any paybacks to justify such investments. 'The rewards of selling several financial products in one package can be spectacular. But few companies have attained this goal. ${ }^{58}$

Companies have been building and maintaining customer relationships and cross-selling products effectively for 
decades without today's expensive technology. In fact, it may be today's emphasis on technology and the huge investment involved that have contributed to low return on CRM investment and perceived lack of success by diverting management attention from fundamental marketing and service issues.

'The strategy [cross-selling] is going to be appropriate for many firms (not all), but the tactical and operational considerations will separate the winners from the losers. ${ }^{59}$ It is not a technology issue. Cross-selling is all about culture and real-time support. The key is to have a well-trained and motivated sales force, who can talk to the customer supported by a real-time (or as close as possible) information system, that is centred around individual customer profitability, to help staff understand all they need about the customer.

It is clear that customer profitability analysis can be used to drive customer relationship management initiatives. Yet, CRM initiatives should not just start with customer profitability analysis, they should end with it as well.

\section{References}

1 Anonymous (2001a) 'CRM in a downturn economy', a Peppers \& Rogers Group White Paper.

2 Howard, L. (2000) 'European banks find cross-selling difficult', National Underwriter, Chicago, 17th April.

3 Ibid.

4 Clark, P. (2000) 'Bank commences cross-selling', B to $B$, Chicago, 25th September.

5 Maughan, S. and Gentle, C. (2001) 'What determines the winners among Europe's retail banks? - How CRM can provide the silver bullet for the future', Goldman Sachs and KPMG Consulting.

6 Ibid.

7 Roosevelt, P. (1999) 'King of the cross-sell', Barron's, Chicopee, 11th October.

8 Johnson, T. (2000) 'The multiple product approach', LIMRA's Market Facts, Hartford, June.

9 Milligan, J. (2000) 'Sandy strikes again', US Banker, New York, October.

10 Cocheo, S. (2000) 'Sales culture: A long way to go', ABA Banking Journal.

11 Anonymous (2001b) 'Tips from the CRM trenches', CRM Forum.

12 Engen, J. (2000) 'E-brokerage's integration challenge', Banking Strategies, Chicago, May/June.

13 Ibid.

14 Thompson, E. (2000) 'CEO and CIO update: The top CRM trends for 2001 - Plus one', Close, Gartner Group.

15 Collins and Harris (2001) 'In search of the elusive promise of financial services CRM', Gartner Research. SPA-13-0295.

16 Close, C. and Eisenfeld, B. (2000) 'Benefits to be gained from e-CRM', Gartner Group.

17 Adolf, R., Grant-Thompson, S., Harrington, W. and Singer, M. (2000) 'What leading banks are learning about big databases and marketing', McKinsey Quarterly.

18 Angel, B. (2000) 'CRM: The upgrade', Canadian Banker, Third Quarter, Vol. 107, No. 3.

19 Forsyth, R. (1998) 'Customer retention and CRM techniques', CRM Forum, www.crm-forum.com

20 Meltzer, M. (1999) 'Using the data warehouse effectively for channel management', January, NCR Corporation, www.rm-forum.com

21 Young, K. (2000) 'CRM lives on', The Banker. Vol. 150, No. 895, September.

22 Johnson (2000) op. cit.

23 Adolf et al. (2000) op. cit.

24 Martocci, R. (2000) 'Teleservices creates multifaceted relationships with banking customers', Call Center Solutions, Norwalk.

25 Groenfeldt, T. (2000) 'Customer data, right here, right now', US Banker, Vol. 110, No. 5.

26 Bellenoit, R. (2000) 'Crossing the sales divide', Best's Review, Vol. 101, No. 5, p. 86, September.

27 Groenfeldt (2000) op. cit.

28 Anonymous (2001b) op. cit.

29 Forsyth (1998) op. cit.

30 Anonymous (2000c) 'Intimacy in the contact centre', American Productivity and Quality Centre (APQC) White paper.

31 Martocci (2000) op. cit.

32 Bellenoit (2000) op. cit.

33 Martocci (2000) op. cit.

34 Curley, B. (2000) 'Royal Bank unearths profitability solution', Bank Systems \& Technology, April.

35 Ratcliff, P. (2000) 'Managing deeper relationships', Mortgage Banking. Vol. 60, Iss. 6, p. 94.

36 Hamblen, M. (2000) 'Instant customer data gives bank sales force an edge', Computerworld, 15th May.

36 Maughan and Gentle (2001) op. cit.

38 Ratcliff (2000) op. cit.

39 Cline, K. (2000) 'No magic bullet', Banking Strategies, November/December.

40 Anonymous (2001d) 'CRM in a down turn economy', A Peppers \& Rogers Group White Paper 6.

41 Keltner, B. (1999) 'Growing sales from existing customers', Sales and Marketing Management, Vol. 151, Iss. 11, p. 135 .

42 Collins, K. (2000) 'Managing customer relationships for increased profitability', Gartner Group (FSCI SPA-12-5880), December.

43 Ibid.

44 Forsyth (1998) op. cit. 
45 Cocheo (2000) op. cit.

46 Collins, K. (2000) 'Measuring CRM success based on profitability', Gartner Group.

47 Ibid.

48 Ibid

49 Meltzer, M. (2000) 'Customer profitability information just isn't enough', CRM Forum Resources, www.crm-forum.com

50 Ibid.

51 Curley (2000) op. cit.

52 Authers, J. (1998) 'Cross-selling's elusive charms',
Financial Times, 16th November.

53 Adolf et al. (2000) op. cit.

54 Coyle, T. (1999) 'Finding your best customers', America's Community Banker, September.

55 Anonymous (2001e) 'Switching accounts to be made easier', The Sunday Times (money section).

56 Coyle, T. (1999) 'Surveys and trends', America's Community Banker, October.

57 Clark (2000) op. cit.

58 Authers (1998) op. cit.

59 Johnson (2000) op. cit. 